\title{
Dynamic response of liquefiable sand improved by microbial-induced calcite precipitation
}

\author{
B. M. MONTOYA* , J. T. DEJONG† and R. W. BOULANGER $\dagger$
}

\begin{abstract}
Microbial-induced calcite precipitation (MICP), a novel bio-mediated ground improvement method, was explored to mitigate liquefaction-prone soils. Geotechnical centrifuge tests were used to evaluate cementation integrity and the response of MICP cemented sands to dynamic loading. The cementation integrity testing reveals a change in behaviour from 'soil like' to 'rock like', with an increase in treatment level. Results from dynamic testing demonstrate a clear increase in resistance to liquefaction of MICP-treated sands compared to untreated loose sand. The MICP sands were treated to varying levels of cementation (light, moderate and heavy cementation levels) and assessed using nondestructive shear wave velocity measurements. The centrifuge models were all subjected to ground motions consisting of sine waves with increasing amplitudes. Accelerations, pore pressures and settlements were measured in the soil during shaking, and the changes in soil behaviour and postshaking shear wave velocity for soils prepared to different cementation levels are discussed. Increased resistance to liquefaction was demonstrated with a decrease in excess pore pressure ratios in the MICP-treated models, as well as in reduced post-shaking settlements; however, surface accelerations were amplified at heavy levels of cementation. A tradeoff between improving liquefaction resistance and minimising undesirable higher surface accelerations needs to be considered when designing the soil improvement level.
\end{abstract}

KEYWORDS: centrifuge modelling; dynamics; ground improvement; liquefaction; sands

\section{INTRODUCTION}

Liquefiable soils are often a major concern for new or rehabilitated infrastructure. These soils generally consist of loose, saturated cohesionless soils with insufficient cyclic shear strength for the expected cyclic load. Liquefiable soils are conventionally improved using a variety of ground improvement methods, including densifying the soil with mechanical energy or injecting a binding agent such as cement, epoxy or silicates (Karol, 2003). However, alternative techniques have emerged that may provide a more natural and sustainable solution. These techniques utilise biological metabolic processes to mediate improvement of soil properties (e.g. strength and stiffness) (DeJong et al., 2010, 2011). Microbial-induced calcite precipitation (MICP) is a natural biologically mediated method to create cementation in situ and improve the mechanical soil properties (DeJong et al., 2006; Whiffin et al., 2007). MICP utilises urea hydrolysis as the chemical reaction to increase the alkalinity of the pore fluid and induce calcite precipitation (Fujita et al., 2008). Sporosarcina pasteurii, a common alkalophilic soil bacterium, has a high urease activity and is used to facilitate the chemical reaction that induces cementation (Mortensen et al., 2011).

Geotechnical centrifuge tests were used to evaluate and establish the potential of MICP treatment to increase soil resistance to liquefaction triggering and to reduce the consequences if liquefaction does occur. The response of the soil at varying levels of treatment, from light to heavy

Manuscript received 1 March 2012; revised manuscript accepted 18 October 2012.

Discussion on this paper closes on 1 August 2013, for further details see p. ii.

* Department of Civil, Construction, and Environmental Engineering, North Carolina State University, Raleigh, NC, USA.

$\dagger$ Department of Civil and Environmental Engineering, University of California, Davis, CA, USA. cementation levels (determined using shear wave velocity measurements), was assessed. The cementation integrity, the pore pressure generation and the soil settlement were among the metrics used to evaluate the response of the treated soil. The MICP-treated soil response was compared to untreated loose and dense soil responses as baselines of poor and adequate behaviour, respectively. Each centrifuge model was constructed identically, except for variation of cementation level or sand density. In addition to evaluating the seismic response of the MICP-treated soil, the cementation integrity of the MICP treatment at varying levels of confinement and cementation was also assessed.

The materials and methods implemented, including the MICP treatment process, are presented first. This is followed by a results and discussion section where the centrifuge results are evaluated. Finally, conclusions regarding the effectiveness of MICP to mitigate the potential for liquefaction-induced damage are presented.

\section{MATERIALS AND METHODS \\ Centrifuge model preparation}

The dynamic centrifuge model tests were conducted on the $1 \mathrm{~m}$ radius Schaevitz centrifuge at the NEES Center for Geotechnical Modeling at the University of California (UC), Davis. The small, flexible shear beam (SFSB) container was used for the centrifuge tests (container design described in Narayanan (1999)). The interior model dimensions were $494 \mathrm{~mm}$ long, $235 \mathrm{~mm}$ wide and $120 \mathrm{~mm}$ deep (model units). Tests were conducted at a centrifugal acceleration of $50 \mathrm{~g}$. Unless otherwise stated, all test results are presented in equivalent prototype units, and the scaling laws used to convert model units to equivalent prototype units are summarised in Kutter (1995). All dynamic centrifuge tests presented herein are listed in Table 1; all of the test information and data are archived at the NEEShub project warehouse (https://nees.org/). Additional information regard- 
Table 1. Centrifuge model test information

\begin{tabular}{l|c|l|c|c}
\hline Test number & $\begin{array}{c}D_{\mathrm{R}} \text { of Ottawa } \\
50-70^{*} \text { sand: } \%\end{array}$ & Treatment level & $\begin{array}{c}\text { Mass of } \\
\text { calcite: }:^{\dagger}\end{array}$ & $\begin{array}{c}\text { Initial } V_{\mathrm{s}}^{\star} \mathrm{m} / \mathrm{s} \\
\text { at } 50 \boldsymbol{g}\end{array}$ \\
\hline MICP-09 & 40 & Untreated & $0 \cdot 0$ & 155 \\
MICP-11 & 85 & Untreated & $0 \cdot 0$ & 180 \\
MICP-10 & 40 & Light cement & $3 \cdot 0$ & 350 \\
MICP-12 & 40 & Moderate cement & $2 \cdot 6$ & 660 \\
MICP-08 & 40 & Heavy cement & $8 \cdot 0$ & 1200 \\
\hline
\end{tabular}

* The Ottawa 50-70 sand used has the following properties: mean particle size, $D_{50}=0.22 \mathrm{~mm}$; coefficient of uniformity, $C_{\mathrm{u}}=1.4$; coefficient of curvature, $C_{\mathrm{c}}=0.9$; specific gravity, $G_{\mathrm{s}}=2.65$; minimum void ratio, $e_{\min }=0.55 ;$ maximum void ratio, $e_{\max }=0 \cdot 87$; quartz mineralogy; round shape.

The mass of calcite for the lightly cemented model (MICP-10) is inflated owing to plugging of the drains at the base of the model container. The plugging allowed for precipitation to occur outside the particle contacts, which increased the mass of calcite without increasing the shear wave velocity, $V_{\mathrm{s}}$, of the soil.

* Average values of $V_{\mathrm{s}}$.

ing the equipment and instrumentation used at the UC Davis centrifuge facility is available at their website (http://nees. ucdavis.edu/).

The centrifuge model consisted of a flat soil surface with a simple structure in the centre of the model; however, the results presented herein are from the behaviour of the free field sensors only. The primary soil deposit consists of a $5.5 \mathrm{~m}$ thick, liquefiable, loose, poorly graded sand layer (Ottawa 50-70; properties presented in Table 1) overlying a thin $0.5 \mathrm{~m}$ thick layer of dense Monterey sand. The thin layer of coarse Monterey sand at the centrifuge container base provided drainage during treatment and enabled uniform saturation. The accelerometers (ACCs) and pore pressure transducers (PPTs) were placed as pairs in a vertical array in the free field (a profile view of the sensors is included later, in Fig. 3). Bender elements were installed in pairs at two depths and three horizontal locations at each depth to track shear wave velocity during treatment, spin-up and before/after shaking. Linear displacements were measured at the soil surface above the free field vertical array of ACCs and PPTs.

Model saturation following treatment consisted of application of 25 in mercury (inHg) vacuum followed by slow saturation with de-aired deionised water. Water was used as the pore fluid to eliminate the potential for negative effects on the MICP process if a different material was used as pore fluid. However, the use of water as the pore fluid instead of a more viscous material (e.g. a solution of hydroxypropyl methylcellulose and water) results in an inconsistency between the scaling laws for the dynamic time and diffusion time. This inconsistency in the time scaling laws results in the generated pore pressures dissipating quicker than they would in the true prototype environment. The model was not flushed with carbon dioxide, as commonly done, because the carbon dioxide is slightly acidic and can degrade the calcite cementation. The response of the soil after the saturation process was consistent with fully saturated soil, including the PPTs measuring the appropriate hydrostatic pore pressures and exhibiting a rapid response during shaking.

Each centrifuge test was subjected to a series of ground motions, as indicated in Table 2. The five ground motions presented consist of sine waves at a prototype frequency of $2 \mathrm{~Hz}$ and increasing amplitudes of maximum base accelerations ranging from about $0 \cdot 1 \mathrm{~g}$ to $0 \cdot 7 \mathrm{~g}$

\section{Biological treatment}

The centrifuge models were biologically treated to varying levels of cementation (as in Table 1). Conceptually, the 'light' cementation (target shear wave velocity, $V_{\mathrm{s}}=300 \mathrm{~m} /$ s) represents an aged sand, the 'moderate' cementation level $\left(V_{\mathrm{s}}=650 \mathrm{~m} / \mathrm{s}\right)$ represents a cemented sand and the 'heavy' cementation level $\left(V_{\mathrm{s}}=1200 \mathrm{~m} / \mathrm{s}\right)$ represents rock-like (i.e. sandstone) material. These target levels of cementation were chosen to cover a spectrum of possible treatment levels; they were also chosen to transition from behaviours that can be described using critical state soil mechanics (e.g. 'soil like') to behaviour that can be better described using fracture mechanics (e.g. 'rock like'). Because of the large model size (and therefore large treatment volume) in comparison to laboratory specimens, the biological treatment process was simplified from previous studies (see Mortensen et al., 2011). The bacteria, S. pasteurii, were grown for $40 \mathrm{~h}$ following American type culture collection (ATCC) recommendations before harvesting. One litre of turbid bacterial suspension $\left(\mathrm{OD}_{600}=0.8-1 \cdot 0\right)$ was diluted with 71 of $0.5 \mathrm{M}$ urea solution. The sand was inoculated with the bacteriaurea medium by flooding the sand at the surface and allowing it to drain freely out of the container bottom (i.e. percolation). Percolation was used as a treatment method

Table 2. Ground motion sequence for centrifuge model tests

\begin{tabular}{l|l|c|c|c|c|c}
\hline \multirow{2}{*}{ Shake no. } & \multirow{2}{*}{ Motion } & \multicolumn{3}{|c|}{ Description } & \multirow{2}{*}{$\begin{array}{c}\text { Range of } a_{\max } \text { at container } \\
\text { base for MICP-8-13 }\end{array}$} & $\begin{array}{c}\text { Average } a_{\max } \text { at } \\
\text { container base }\end{array}$ \\
\cline { 3 - 6 } & & Displacement:* in & Frequency:* Hz & No. of cycles & & $0.12 \boldsymbol{g}$ \\
\hline 1 & Sinusoidal & $0 \cdot 008$ & 100 & 15 & $0 \cdot 11-0 \cdot 15 \boldsymbol{g}$ & $0 \cdot 24 \boldsymbol{g}$ \\
2 & Sinusoidal & $0 \cdot 015$ & 100 & 15 & $0 \cdot 21-0 \cdot 27 \boldsymbol{g}$ & $0 \cdot 47 \boldsymbol{g}$ \\
3 & Sinusoidal & $0 \cdot 03$ & 100 & 15 & $0 \cdot 43-0 \cdot 52 \boldsymbol{g}$ & $0 \cdot 65 \boldsymbol{g}$ \\
5 & Sinusoidal & $0 \cdot 04$ & 100 & 15 & $0 \cdot 59-0 \cdot 68 \boldsymbol{g}$ & $0 \cdot 74 \boldsymbol{g}$ \\
\hline
\end{tabular}

* The displacement and frequency commands sent to the shaker are in model scale. Therefore, the equivalent prototype frequency of the sine waves is $2 \mathrm{~Hz}$. 
because preliminary laboratory tests found that percolating the treatment fluid through free-draining soil resulted in similar or improved uniformity of cementation distribution compared to specimens that underwent treatment by a more traditional injection method. The mass of calcite was measured in each centrifuge model, and cementation was found to be uniform both laterally and vertically within the model, with a standard deviation in mass of calcite of about $20 \%$. In addition, percolation provided a more controlled treatment environment for the centrifuge container than an injection scheme, such as arrays of injection and extraction wells. Although percolation was the chosen treatment method for the model preparation, injection methods may be more realistic for field treatments. Based on microscale investigations by the research team, the calcite precipitation is similar for percolation and injection methods; therefore, the behaviour of the cemented sands from the MICP treatments is similar whether percolation or injection methods were used. The behaviour presented herein from the models prepared using a percolation treatment method can be expected to be representative of MICP-treated sands from injection methods, if the injection procedures are successful in obtaining similar degrees of treatment uniformity. For surficial stability during treatment, a neoprene mesh and $\frac{1}{2}$ in crushed rock were placed on the surface of the sand. The crushed rock also provided a light overburden that increased the amplitude of the received bender element signal at $1 \mathrm{~g}$.

The cementation process was initiated after the inoculated bacteria were retained in the model for at least $6 \mathrm{~h}$ to allow bacterial attachment to sand grains. Urea-calcium cementation medium ( $1 \mathrm{M}$ urea: $0 \cdot 5 \mathrm{M}$ calcium chloride) was used to induce ureolytic-driven calcite precipitation. Cementation treatments were repeated every $4-6 \mathrm{~h}$ until the target shear wave velocity (see Table 1) was attained.

The cementation increase was monitored in real time using shear wave velocity. Bender elements (Piezo Systems, Inc.) required special preparation for the highly conductive environmental conditions (Montoya et al., 2012). Shear waves were applied using a $9 \mathrm{~V}, 100 \mathrm{~Hz}$ square wave and the received bender element response was recorded in a LabView (National Instruments, Austin, TX) program (Brandenberg et al., 2008). The shear wave velocity was determined from visually interpreted travel times and measured bender element spacing in the model (including corrections for bender element movement from soil deformations).

\section{Cyclic direct simple shear test}

Cyclic direct simple shear (DSSc) tests were performed to compare to the centrifuge tests. The DSSc tests were performed with a Geotac DigiShear apparatus configured for constant-volume shear tests with full drainage to the specimen. This configuration, the equivalent undrained methodology developed by the Norwegian Geotechnical Institute, allows for a constant volume, or 'undrained', test to be performed, even though drained conditions are maintained (e.g. sample drain lines are open) and no pore pressures are developed. The change in normal stress measured during the constant-volume test is assumed to be the equivalent to the excess pore pressure generation under true undrained loading. The specimens were $63.5 \mathrm{~mm}$ in diameter, and approximately $16.5 \mathrm{~mm}$ tall. The loose sand specimens were consolidated to a vertical effective stress of $100 \mathrm{kPa}$, and then underwent the MICP treatment procedure outlined above for the centrifuge tests. The specimens were then subjected to strain-controlled loading at a strain rate of $50 \%$ shear strain per hour. If, after a significant number of cycles, shear wave velocities and test data indicated the specimen had neither yielded nor changed structurally, the cyclic stress limits were increased to accelerate the test.

\section{BIOCEMENTATION INTEGRITY DURING STRESS CYCLING}

The integrity of the cementation is dependent on the confinement stress and the stress at which the cementation was precipitated (i.e. curing stress). For centrifuge testing, the cementation treatments occurred at $1 g$, whereas dynamic shaking occurred at $50 \mathrm{~g}$. The influence of the increased $\boldsymbol{g}$ field on cementation integrity was quantified to ensure the target $V_{\mathrm{s}}$ at $50 \mathrm{~g}$ was consistently achieved.

The effect of the change of confinement on the cementation integrity was monitored using shear wave velocity measurements on specimens prepared to different degrees of cementation and then subjected to slow cycles of vertical stress by increasing and decreasing the centrifugal acceleration. As the centrifuge model spun up from $1 \mathrm{~g}$ to $50 \mathrm{~g}$, bender elements were used to measure the shear wave velocity at discrete centrifugal accelerations. Results are presented in Fig. 1 as shear stiffness plotted against effective vertical stress. When the confinement increases, the stress at the contacts between the sand particles increases, which results in an increase in shear wave velocity. However, the cementation has a preference to precipitate at the particle contacts and, as the stresses at the contacts increase, cementation may be damaged (DeJong et al., 2010). The extent of cementation degradation depends on the cementation level and loading path. Therefore, as the confinement stress changes, corresponding changes in the measured shear wave
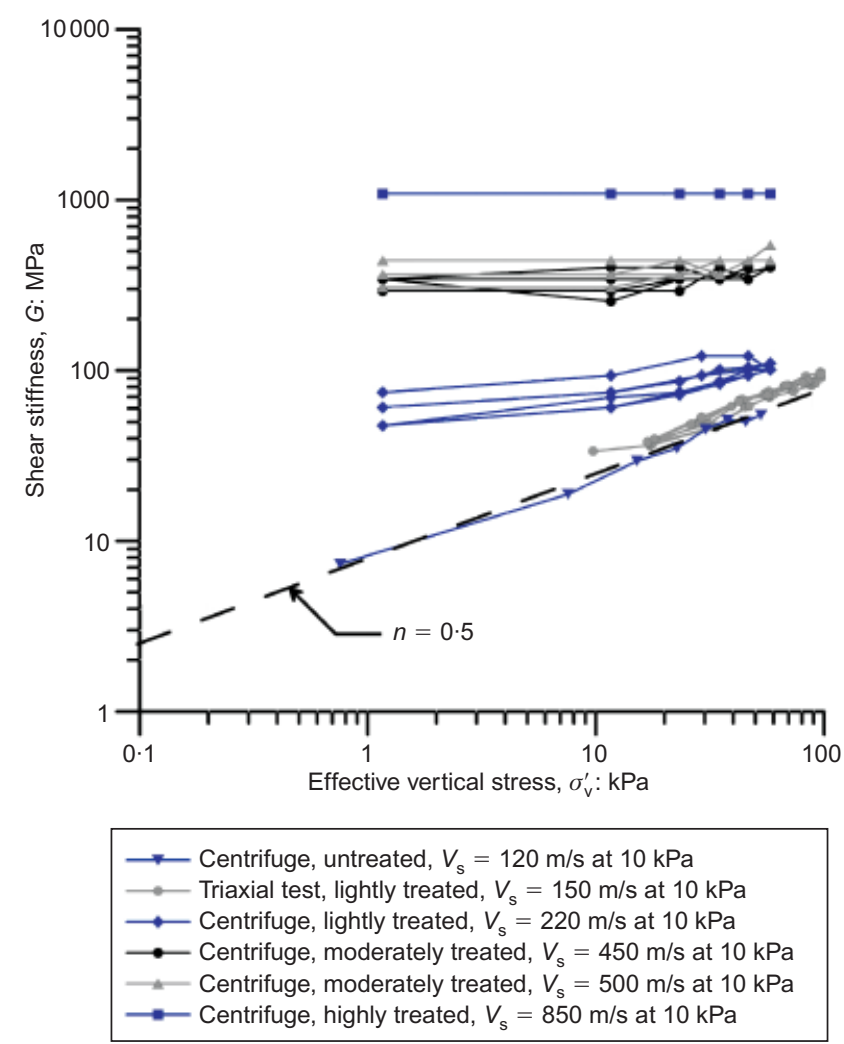

Fig. 1. Variation of small-strain shear modulus of untreated to highly treated sands during repeated cycles of increasing and decreasing effective confining stress. The black dashed line has a slope of $n=0 \cdot 5$, following the general relationships for untreated soils outlined by Stokoe et al. (1985) and Hardin \& Black (1968). This black line is used as a reference to compare the results of both untreated and cemented soils 
velocity are due to the increase (or decrease) in confinement and the degradation of the cementation.

Effects of confinement on shear stiffness, $G$, are well established for uncemented soils (e.g. Hardin \& Black, 1968; Stokoe et al., 1985). In general, the relationship of $\log$ $G$ against $\log \sigma_{\mathrm{v}}^{\prime}$ for uncemented sands has a slope of 0.5 (slope indicated by dashed line in Fig. 1). This slope is similar to the value obtained in the tests with untreated sand specimens.

The slope of $\log G$ against $\log \sigma_{\mathrm{v}}^{\prime}$ for cemented sands varies as a function of cementation level (Fig. 1). As cementation increases, the slope decreases until the stiffness is no longer dependent on the confinement stress (e.g. slope equal to zero). In general, as the cementation degrades, the slope of the $\log G$ against $\log \sigma_{\mathrm{v}}^{\prime}$ relationship begins to increase, becoming more similar to that of the uncemented sand (as illustrated in Fig. 2 and discussed below).

The influence of confinement and cementation degradation on the shear stiffness of one specimen of MICP-treated sand is presented in Fig. 2. A lightly cemented sand $\left(V_{\mathrm{s}}=220 \mathrm{~m} / \mathrm{s}\right.$ at $10 \mathrm{kPa}$ ) was subjected to cycles of vertical stress loading and unloading utilising the centrifuge. As the centrifuge spins up from $1 \boldsymbol{g}$ to $25 \boldsymbol{g}$ (cycle 0, Fig. 2), the shear stiffness continually increases (non-linearly). Above $25 \mathrm{~g}$, the cementation begins to degrade and the shear stiffness remains constant, even with an increase in confinement (higher $g$ level). The cementation (shear stiffness) degrades further with an increase to $50 \mathrm{~g}$. During unloading (spin down to $1 \mathrm{~g}$ ), the cumulative cementation degradation is represented by the permanent reduction of the shear stiffness (cycle 1, Fig. 2). Cementation continues to degrade with another cycle, producing a further decrease in shear stiffness (cycle 2, Fig. 2). After two full loading-unloading cycles, the behaviour of the cemented sand stabilises, with the shear stiffness no longer degrading (cycle 3, Fig. 2). This final slope is still lower than the slope of the uncemented sands $(n<0 \cdot 5)$. This behaviour indicates that the light cementation, although slightly degraded, still improves the small-strain stiffness compared to the untreated sand. The improvement in stiffness after degradation of the cementation is also influenced by the decreased void ratio from the precipitated calcite in the voids (whether intact to sand grains or degraded into fines). As an example, an approximate decrease in void ratio of 0.03 can be expected for about $1.5 \%$ mass of calcite (Weil

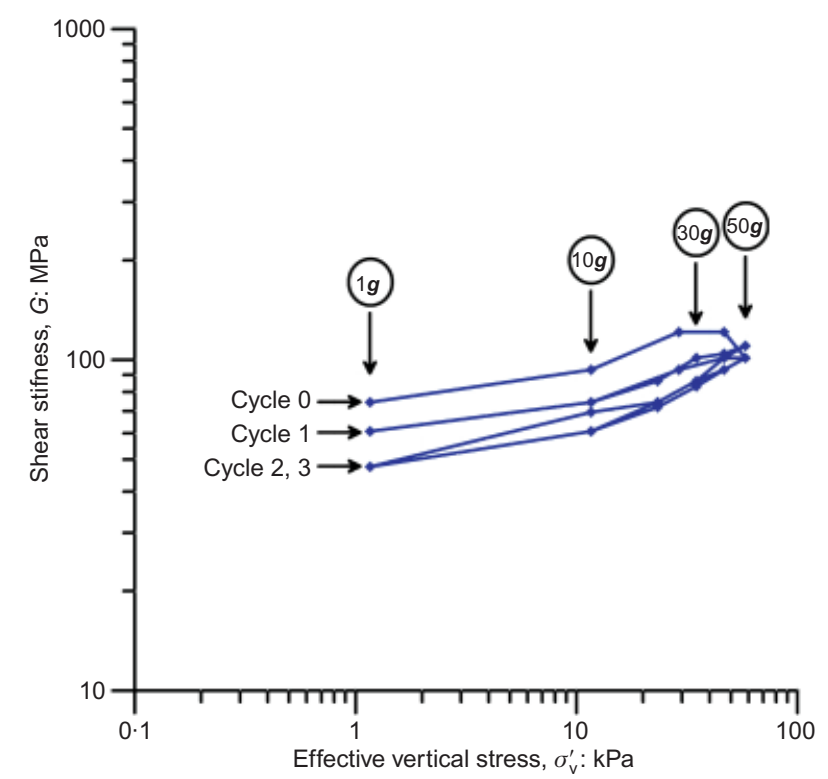

Fig. 2. Cementation integrity of lightly cemented sand $\left(V_{\mathrm{s}}=220 \mathrm{~m} / \mathrm{s}\right.$ at $\left.10 \mathrm{kPa}\right)$ et al., 2011). Similar cementation degradation behaviour with stress cycling is also evident in the moderately cemented sands (Fig. 1, $V_{\mathrm{s}}=450-500 \mathrm{~m} / \mathrm{s}$ ). However, once the cementation becomes sufficient such that the soil stiffness is no longer dependent on the confinement stress, the cementation does not degrade with cyclic loading-unloading (Fig. 1, $V_{\mathrm{s}}=850 \mathrm{~m} / \mathrm{s}$ ).

By understanding the relationship between shear stiffness and confining stress at the various levels of cementation, the bio-treatment levels could be designed for the centrifuge experiment. The centrifuge models were treated at $1 g$ to a certain value of shear wave velocity so that the desired shear wave velocity was achieved at a confinement of $50 \mathrm{~g}$. The results from the cementation integrity testing (Fig. 1) were used to design the $1 \boldsymbol{g}$ treatment levels.

\section{FREE-FIELD DYNAMIC PERFORMANCE} Results

The response of the free-field MICP-treated soil to dynamic loading is examined using time histories from the following two events: sine waves with a 'low' $a_{\max }$ value (about $0.2 \mathrm{~g}$ ) and a 'high' $a_{\max }$ value (about $0.7 \mathrm{~g}$ ) at the container base. Results from five models are presented: loose untreated sand, dense untreated sand, loose lightly cemented sand, loose moderately cemented sand, and loose heavily cemented sand (Table 1). The response of each soil is compared to the untreated loose sand (considered the baseline). The dynamic response from each sine wave amplitude motion (Table 2) is summarised at the end of the discussion.

Baseline untreated loose and dense sand response. The untreated loose soil response at the low shaking level (Fig. 3, dashed line) reached excess pore pressure ratios $\left(r_{\mathrm{u}}=\right.$ excess pore pressure/vertical effective stress) ranging from 0.4 at depth to 1.0 near the surface of the profile. The untreated loose sand developed similar levels of surface acceleration across all the cycles of the ground motion, even though liquefaction occurs (e.g. $r_{\mathrm{u}} \sim 100 \%$ ) near the surface (Fig. 3, dashed line). At low shaking levels, the acceleration amplification is expected to be equal to or greater than 1.0 and largely in phase with the base motion because the base motion frequency $\left(f_{\text {in }}=2 \mathrm{~Hz}\right)$ is smaller than the natural soil frequency $\left(f_{\mathrm{n}}=6.5 \mathrm{~Hz}\right)$. When the soil softens due to seismic loading, the natural frequency reduces (Table 3 ), yet it remains larger than the base motion frequency $\left(f_{\text {in }}=2 \mathrm{~Hz}\right)$ such that the amplitude and phasing of the surface motion did not change dramatically (Fig. 3, dashed line).

The untreated loose sand response at the high shaking level (Fig. 4, dashed line) has a notable difference in behaviour relative to that of the lower shaking level. The accelerations, especially the near-surface recording (AH 7), exhibit a spiky shape, indicating strain-stiffening non-linearity in the stress-strain behaviour of the soil (Chou \& Kutter, 2008). When the soil is undergoing strain-stiffening behaviour during cyclic loads, a shock wave may form that corresponds to discontinuities in shear stress and large spikes in the acceleration record (Chou \& Kutter, 2008). This strain-stiffening non-linearity behaviour has also been observed in laboratory tests (Ishihara, 1985) and field seismic recordings (Youd \& Holzer, 1994). The non-linearity in the centrifuge time history is more pronounced at the high shaking level than at the lower shaking amplitudes, as expected. In addition, the excess pore pressures generated are greater than at the lower shaking levels. At the high shaking level, the untreated loose soil generated significant excess pore pressures at all depths, with $r_{\mathrm{u}}$ values of 0.7 at depth to 1.0 near the surface. High pore pressure continues until the end of shaking, after which 

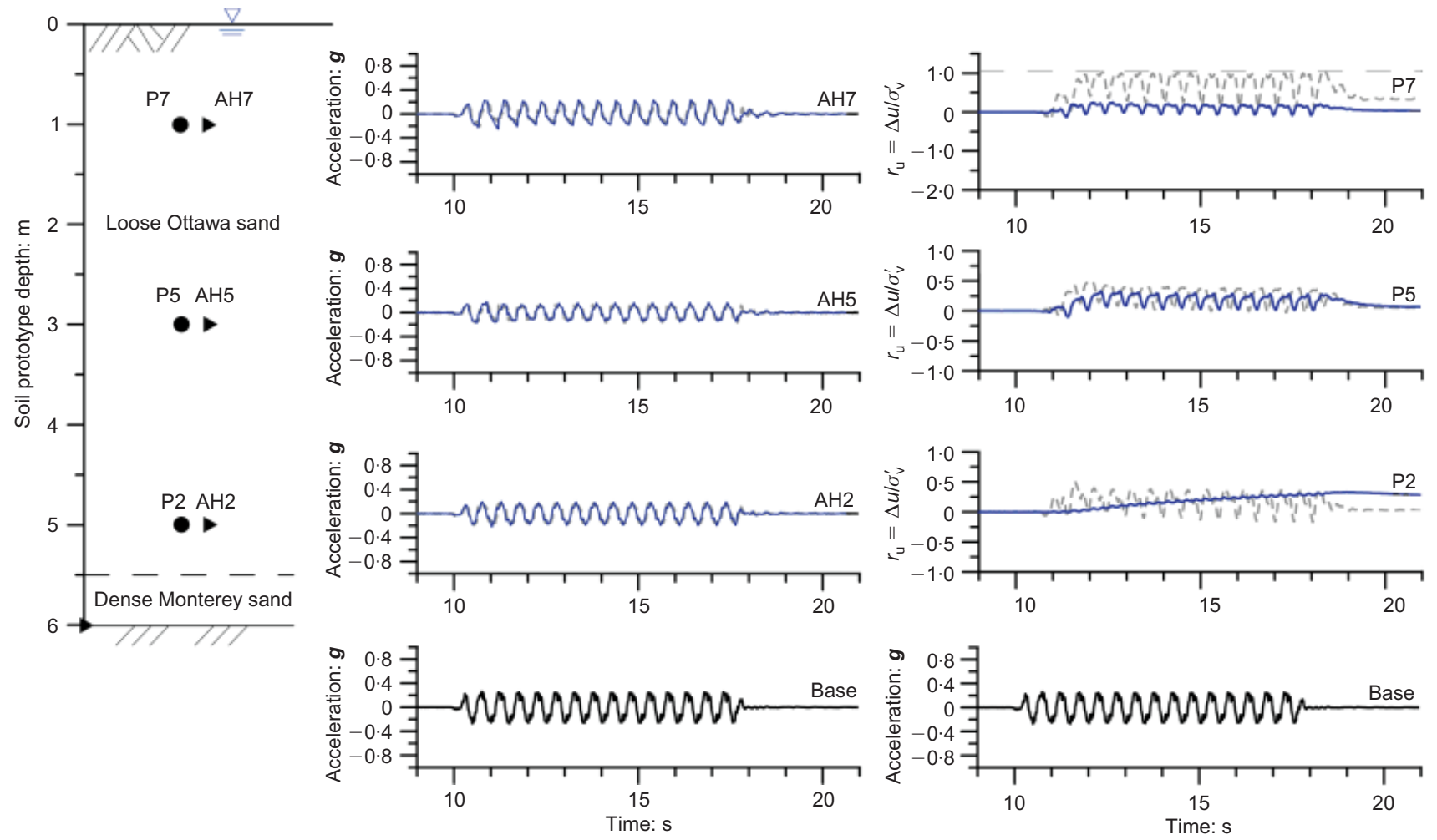

Fig. 3. Free-field untreated dense sand behaviour under dynamic loading (base $a_{\max }=0 \cdot 2 g$ ) (solid line) compared to untreated, loose sand behaviour under the same dynamic load (dashed line)

Table 3. Natural frequencies of the soil column for each centrifuge model test

\begin{tabular}{|c|c|c|c|c|c|c|c|}
\hline Test number & $\begin{array}{l}\text { Initial } V_{\mathrm{s}}: \mathrm{m} / \mathrm{s} \\
\quad \text { at } 50 \mathrm{~g}\end{array}$ & $\begin{array}{c}\text { Initial } f_{\mathrm{n}}: * \\
\mathrm{~Hz}\end{array}$ & Wavelength: $\mathrm{m}$ & $\begin{array}{l}\text { Initial } G_{\max }: \\
\mathrm{MPa}\end{array}$ & $\begin{array}{c}\text { Degraded } f_{\mathrm{n}}:^{\dagger} \\
\mathrm{Hz}\end{array}$ & Wavelength: m & $\begin{array}{l}\text { Ratio of degraded to } \\
\text { initial } G_{\max }^{\dagger}\end{array}$ \\
\hline $\begin{array}{l}\text { MICP-09 } \\
\text { MICP-11 } \\
\text { MICP-10 } \\
\text { MICP-12 } \\
\text { MICP-08 }\end{array}$ & $\begin{array}{r}155 \\
180 \\
350 \\
660 \\
1000\end{array}$ & $\begin{array}{l}6 \cdot 5 \\
7 \cdot 5 \\
15 \\
28 \\
42\end{array}$ & $\begin{array}{l}77 \cdot 5 \\
90 \cdot 0 \\
175 \\
330 \\
500\end{array}$ & $\begin{array}{c}36 \cdot 0 \\
48 \cdot 6 \\
184 \\
653 \\
1500\end{array}$ & $\begin{array}{l}5 \cdot 8 \\
8 \cdot 7 \\
12 \\
20 \\
22\end{array}$ & $\begin{array}{l}70 \cdot 0 \\
104 \\
140 \\
235 \\
265\end{array}$ & $\begin{array}{l}0.82 \\
1 \cdot 34 \\
0 \cdot 64 \\
0.51 \\
0.28\end{array}$ \\
\hline
\end{tabular}

* The natural frequency of the soil prior to dynamic loading (e.g. stiffness degradation). The natural frequency of the soil column is: $f_{\mathrm{n}}=V_{\mathrm{s}} / 4 H$.

${ }^{\dagger}$ Determined using the $V_{\mathrm{s}}$ after shaking, which is representative of the degraded cemented material.

pore pressure begins to dissipate. Offsets between the initial and final pore pressure values are attributable to transducer settlements that have taken place during and after shaking.

The response of the dense untreated sand to dynamic loading is significantly improved compared to the untreated loose soil. Under the $0 \cdot 2 \boldsymbol{g}$ sine wave motion, the acceleration-time histories are equivalent to the recordings from the loose sand model (Fig. 3, solid line). The acceleration time histories during the $0.7 \mathrm{~g}$ sine wave event have similar phasing when compared to the loose untreated sand; however, the acceleration amplitude is increased (Fig. 4, solid line). The acceleration amplitude at the deeper soil layer is equivalent, and the wave amplifies as it approaches the soil surface $(1.5 \times)$ compared to the loose sand with similar nonlinearity evident in the recordings. The dense sand response also experienced lower generation of pore pressures at both levels of shaking, with the $r_{\mathrm{u}}$ value about 0.3 at depth and at about 0.8 near the surface.

Biotreated sand response. The behaviour of the lightly cemented loose sand $\left(V_{\mathrm{s}}=350 \mathrm{~m} / \mathrm{s}\right)$ presented in Figs $5-8$ shows improved soil behaviour similar to the dense sand. The acceleration-time histories at $0 \cdot 2 \boldsymbol{g}$ exhibit similar phasing and similar amplitudes compared to the loose sand. At the higher shaking level, acceleration-time histories exhibit similar phasing with slightly larger amplitudes than the loose sand at the deeper depths (1.2 times) and increasing amplitudes near the surface $(1 \cdot 1-1.5$ times the loose sand amplitude). The lightly cemented sand response also experienced significantly lower pore pressure generation at both shaking levels, with the $r_{\mathrm{u}}$ value reaching 0.5 at depth and only $\sim 0.3$ near the surface.

The moderately cemented sand (Figs 5-8) also shows improved soil behaviour, similar to that of the lightly cemented and dense untreated sands. At $0 \cdot 2 \mathrm{~g}$ dynamic loading, the acceleration-time histories indicate similar phasing and amplitudes compared to those of the loose sand. The acceleration records from the $0.7 \mathrm{~g}$ dynamic loading show similar phasing to the loose untreated sand, with amplitudes that are equivalent at the lower depth, lower at the mid-depth $(0.5$ times) and about 1.6 times higher near the surface. The generated excess pore pressures are significantly lower at both shaking levels (e.g. maximum $r_{\mathrm{u}}=0.2$ at $0 \cdot 2 \mathrm{~g}$ shaking and maximum $r_{\mathrm{u}}=0.6$ at $0.7 \mathrm{~g}$ shaking).

The dynamic response of the heavily cemented sand (Figs $5-8$ ) is largely similar to that of the moderately and lightly cemented sands. At $0 \cdot 2 \boldsymbol{g}$ dynamic loading, the acceleration- 

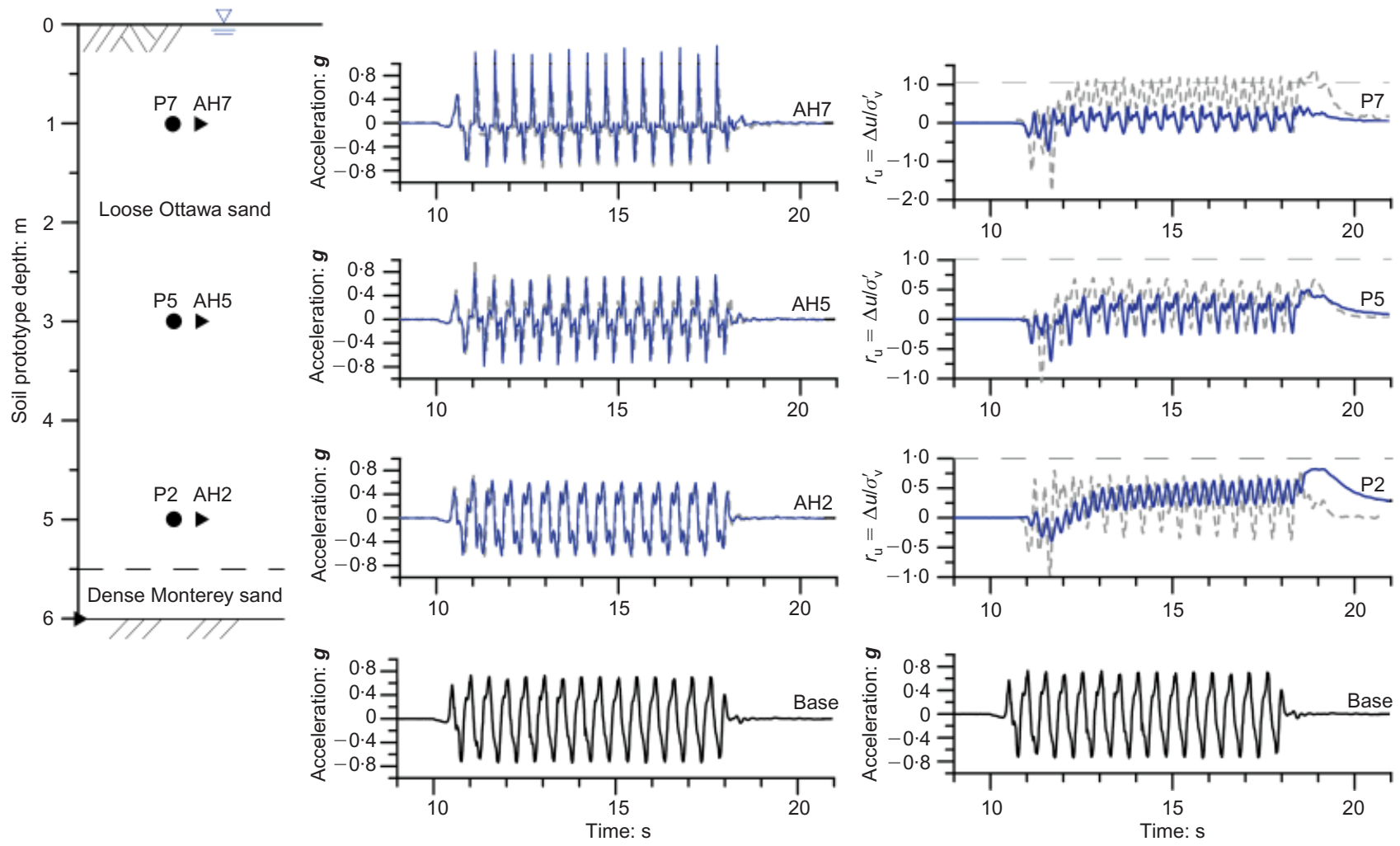

Fig. 4. Free-field untreated dense sand behaviour under dynamic loading (base $a_{\max }=0 \cdot 7 \mathrm{~g}$ ) (solid line) compared to untreated, loose sand behaviour under the same dynamic load (dashed line)
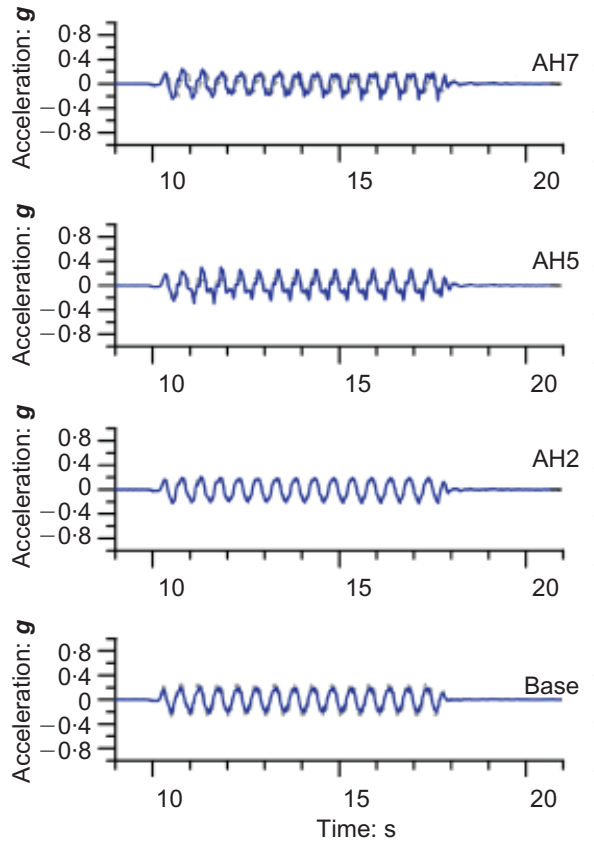

(a)
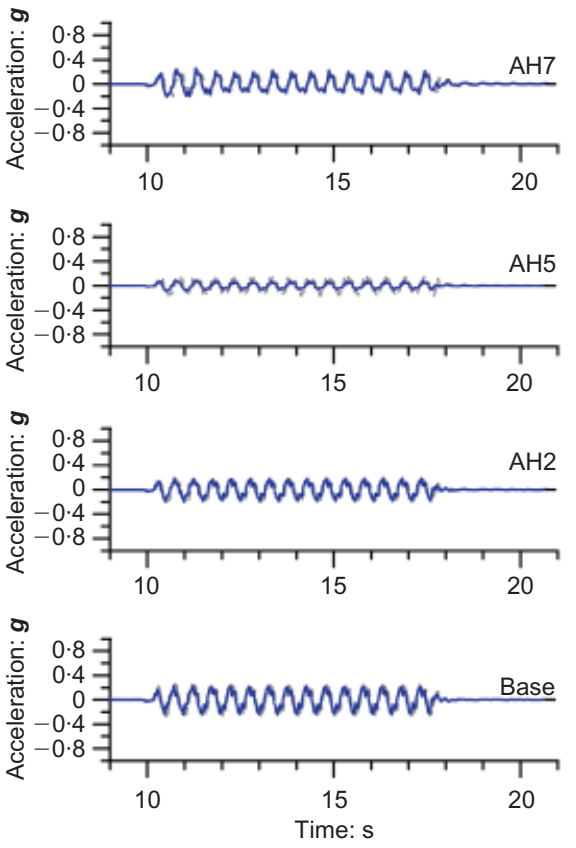

(b)
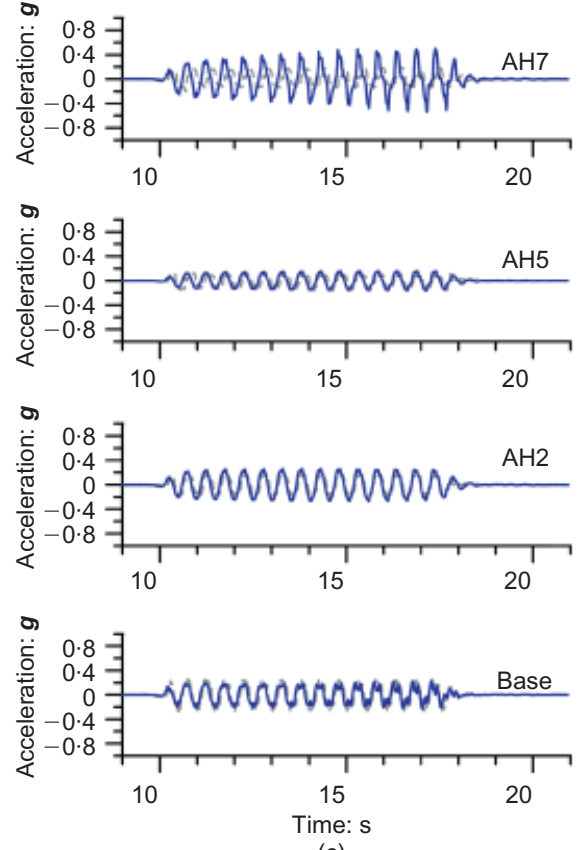

(c)

Fig. 5. Free-field cemented sand acceleration-time histories under dynamic loading (base $a_{\max }=0 \cdot 2 \mathrm{~g}$ ) (solid line) compared to untreated, loose sand behaviour under the same dynamic load (dashed line): (a) lightly cemented sand; (b) moderately cemented sand; (c) heavily cemented sand

time histories at the lower and mid-depths contain similar phasing and amplitudes compared to those of the moderately and lightly cemented sands. However, the near-surface acceleration starts at a similar amplitude and then begins to increase incrementally in amplitude during the shaking event up to about twice that of the moderately and lightly cemented sand. This increase in acceleration with each cycle of $0 \cdot 2 \mathrm{~g}$ shaking was accompanied by a transition to a spikey response. At $0 \cdot 7 \boldsymbol{g}$ dynamic loading, the acceleration recordings at mid-depth and near the surface exhibit one-sided spikes for all three cementation levels, similar to those shown in Chou \& Kutter (2008), which indicate strainstiffening non-linearity. The heavily, moderately and lightly cemented sands also experienced similar mean levels of excess pore pressures at both levels of shaking, although the transient spikes in $r_{\mathrm{u}}$ varied in magnitude at the various 

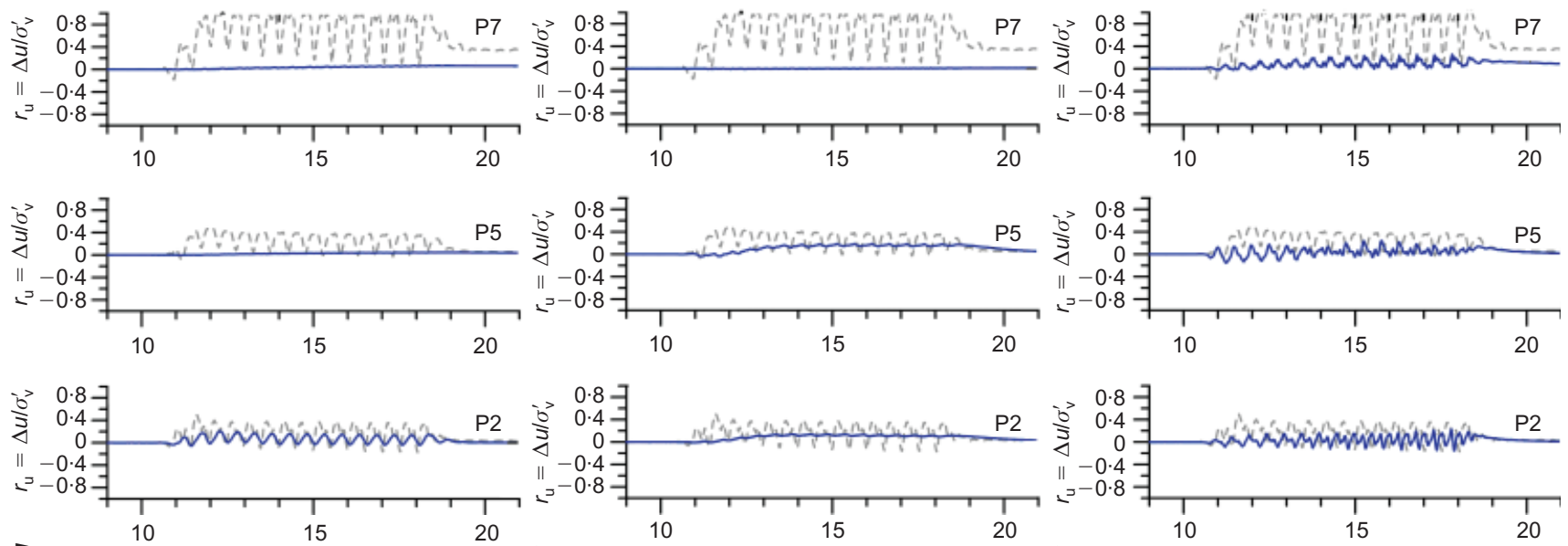

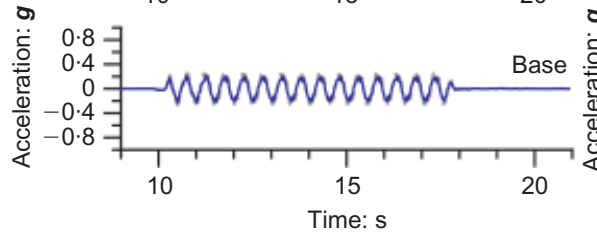

(a)

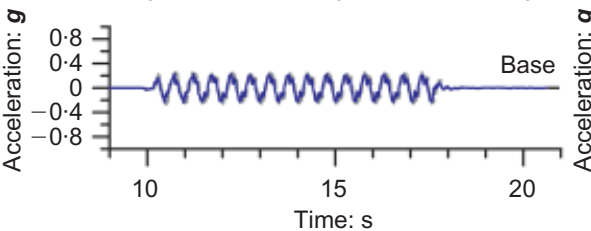

(b)

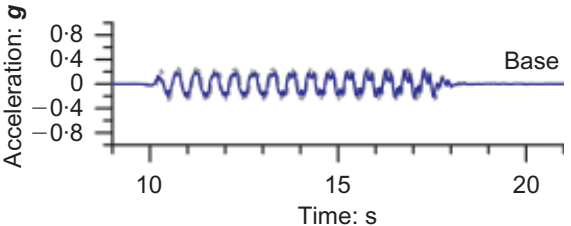

(c)

Fig. 6. Free-field cemented sand normalised excess pore pressure-time histories under dynamic loading (base $a_{\text {max }}=0 \cdot 2 g$ ) $($ solid line) compared to untreated, loose sand behaviour under the same dynamic load (dashed line): (a) lightly cemented sand; (b) moderately cemented sand; (c) heavily cemented sand
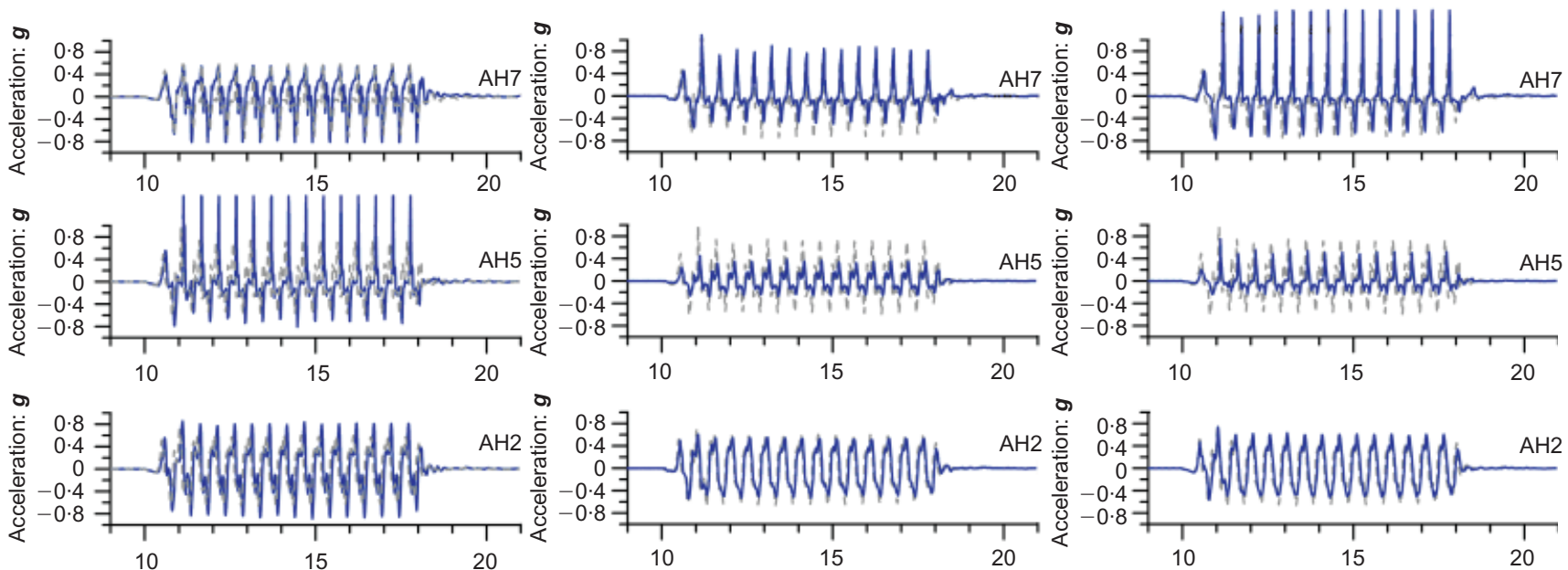

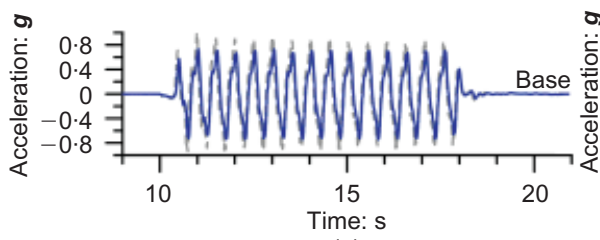

(a)

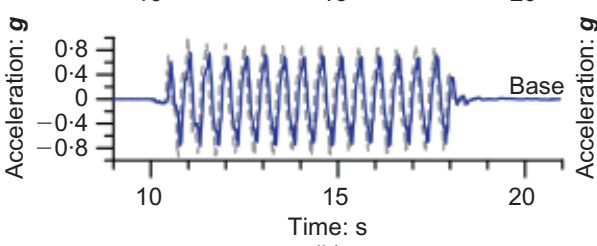

(b)

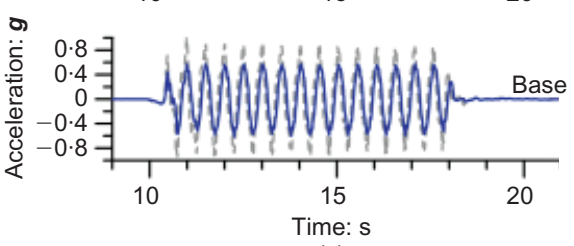

(c)

Fig. 7. Free-field cemented sand acceleration-time histories under dynamic loading (base $a_{\max }=0 \cdot 7 \mathrm{~g}$ ) (solid line) compared to untreated loose sand behaviour under the same dynamic load (dashed line): (a) lightly cemented sand; (b) moderately cemented sand; (c) heavily cemented sand

depths in these three models. The heavily cemented sand had peak $r_{\mathrm{u}}$ values up to 0.25 at depth and about 0.65 near the surface in the stronger shaking event. The positive spikes in the pore pressure are in phase with the spikes of the acceleration-time history at the same elevation, which indicates that this feature may be due to a temporary pulse in mean stress (e.g. from compression waves reflecting off the side walls). The fact that the spikes in pore pressure are slightly one-sided may indicate an asymmetric gapping or contact against the end walls. Even with this behaviour, the amplitudes of the generated excess pore pressures are still less than an $r_{\mathrm{u}}$ value of 1.0 .

\section{Discussion}

The MICP-treated soils developed lower levels of excess pore pressure and higher peak ground surface accelerations for similar base input accelerations compared to the loose untreated sand baseline. The acceleration-time histories at $0 \cdot 2 \mathrm{~g}$ are, in general, quite similar to that of the loose sand 

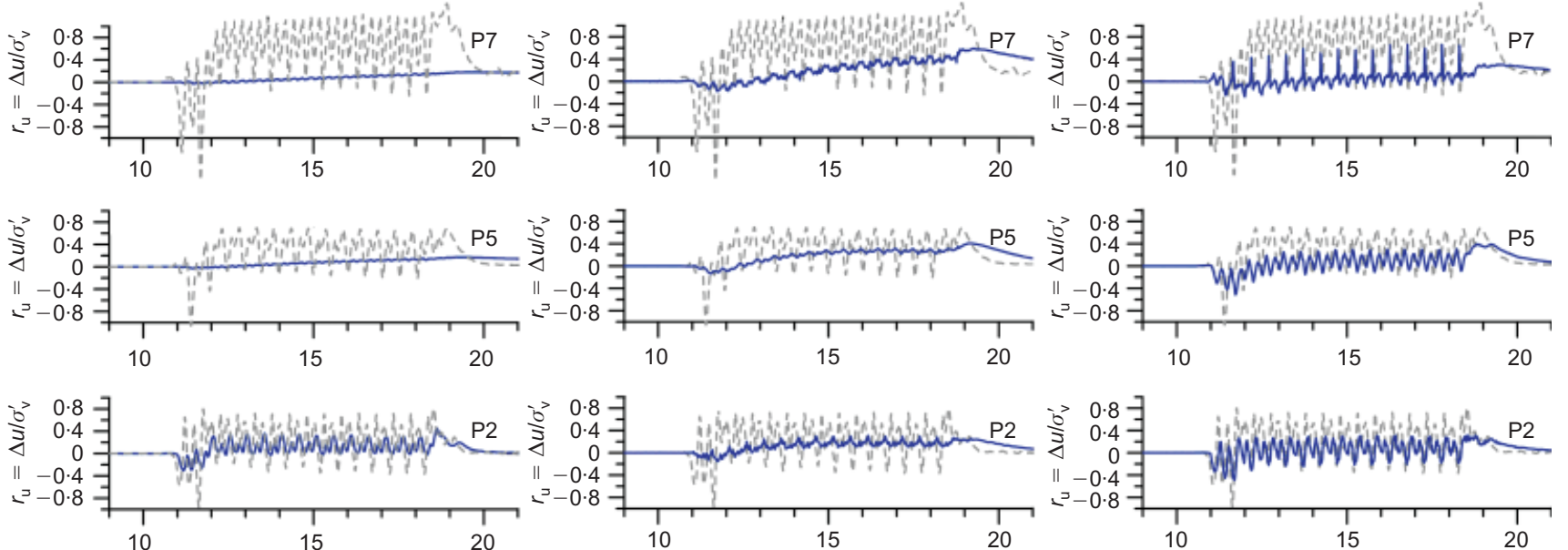

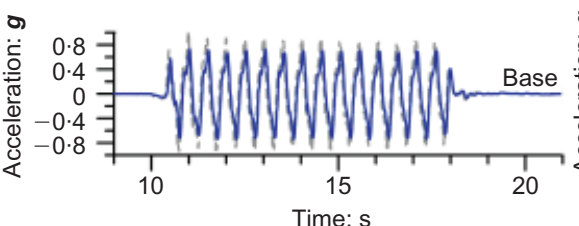

(a)

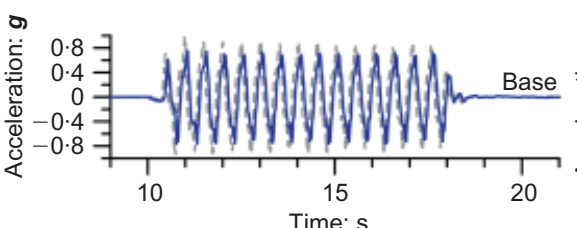

(b)

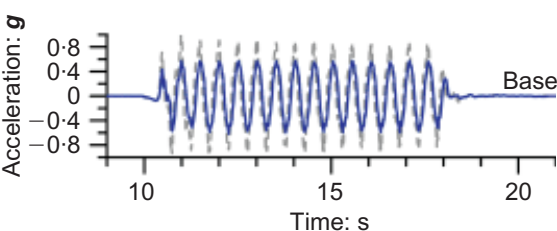

(c)

Fig. 8. Free-field cemented sand normalised excess pore pressure-time histories under dynamic loading (base $a_{\text {max }}=0 \cdot 7 g$ ) (solid line) compared to untreated loose sand behaviour under the same dynamic load (dashed line): (a) lightly cemented sand; (b) moderately cemented sand; (c) heavily cemented sand

(equivalent or less in amplitude, and in phase with the ground motion) (Fig. 5). The pore pressures generated from the $0 \cdot 2 \mathrm{~g}$ dynamic event are significantly reduced in the MICP-treated soils compared to the loose untreated sand (Fig. 6). Under $0 \cdot 7 \mathrm{~g}$ dynamic loading, the acceleration-time histories are similar, with an increase in amplitude near the surface (about $1 \cdot 1$ up to $2 \cdot 0$ times that of loose sand) (Fig. 7). The MICP-treated sand shows similar spikiness as the loose untreated sand, and it is relatively in phase with the ground motion. The pore pressures generated under $0.7 \mathrm{~g}$ dynamic loading are also significantly reduced compared to those in the loose untreated sand and are well below $r_{\mathrm{u}}=1.0$ (Fig. 8).

The shaking-induced settlements in the free field indicate a reduction in settlements of MICP-treated soils compared to loose untreated sand. The cumulative settlements contain similar settlement trends to that of the dense sand until the cementation begins to break down, as indicated by the $V_{\mathrm{s}}$ measurements (Fig. 9). Once a significant amount of cementation degrades, the settlements of the MICP-treated soil increase in magnitude and approach that of the loose untreated sand. The point at which this occurs is indicated within the $V_{\mathrm{s}}$ plots in Fig. 9; A indicates significant cementation degradation and settlement accumulation for the lightly cemented sand, B indicates significant cementation degradation and settlement accumulation for the moderately cemented sand, $\mathrm{C}$ indicates initial cementation degradation in the heavily cemented sand (limited settlement accumulation), and $\mathrm{C}^{\prime}$ indicates additional cementation degradation and settlement accumulation in the heavily cemented sand. The amount of settlement of the MICP-treated sand remains below that of the loose sand; the improvement from the cementation is still realised, even after the cementation is degraded. The loose untreated sand experiences comparatively large settlements, especially above a maximum nearsurface acceleration, $a_{\max }$, of $0.4 \mathrm{~g}$. As indicated in Fig. 9, the cumulative settlement pattern of the lightly cemented sand begins to deviate from the dense, untreated sand and trends towards that of the loose untreated sand around an $a_{\max }$ value of $0.8 \mathrm{~g}$. The cumulative settlement pattern of the moderately cemented sand begins to deviate from the dense sand above an $a_{\max }$ value of about $1.0 \mathrm{~g}$; the moderately cemented sand does not experience the accumulation of settlements within a narrow surface $a_{\max }$ range that the loose and lightly cemented sands do. The cumulative settlements of the heavily cemented sands are less than the dense, untreated sands at an equivalent $a_{\max }$. However, the settlements appear to be approaching the dense sand settlements at an $a_{\max }$ value of about $1.5 \mathrm{~g}$, at which point the settlements appear to be accumulating at a narrow surface $a_{\max }$ range, as seen in the loose and lightly cemented sand. This behaviour may indicate that the cementation is degrading; however, the shear wave velocity of the heavily cemented sand appears to begin degrading at lower $a_{\max }$ values (above about $0 \cdot 5 \mathrm{~g}$ ).

In theory, the cemented sand would resist shaking-induced settlements until a threshold acceleration is reached (approximately indicated by the letters $\mathrm{A}, \mathrm{B}$ and $\mathrm{C}^{\prime}$ in Fig. 9), at which point the cementation would break down and additional settlements are experienced. In general, this is the behaviour observed in the free-field data, as described above. The early cementation degradation of the heavily cemented sand may be due to the nature of the cementation bonds within the soil (e.g. at particle contacts as opposed to spanning across particle faces); some cementation is strong enough to stay intact up to larger shear stresses, whereas some cementation is strong enough to increase the shear wave velocity but degrade quickly at even low levels of shaking. The incremental settlement (Fig. 9) also indicates that the MICP-treated sands experience less settlement than the loose untreated sand at all levels of shaking, and in general have similar magnitude settlements to the dense sand until the cementation is degraded. In addition, the incremental settlement also indicates that the soil tested experiences a peak magnitude of settlement from a single shaking event, after which less settlement is experienced (likely due to sand densification from previous shaking events). The peak magnitude of incremental settlement occurs at about $0 \cdot 5 \mathrm{~g}$ for the loose untreated sand, $0.7 \mathrm{~g}$ for lightly cemented sand and about $1.0 \mathrm{~g}$ for the heavily cemented sand (the moderately 

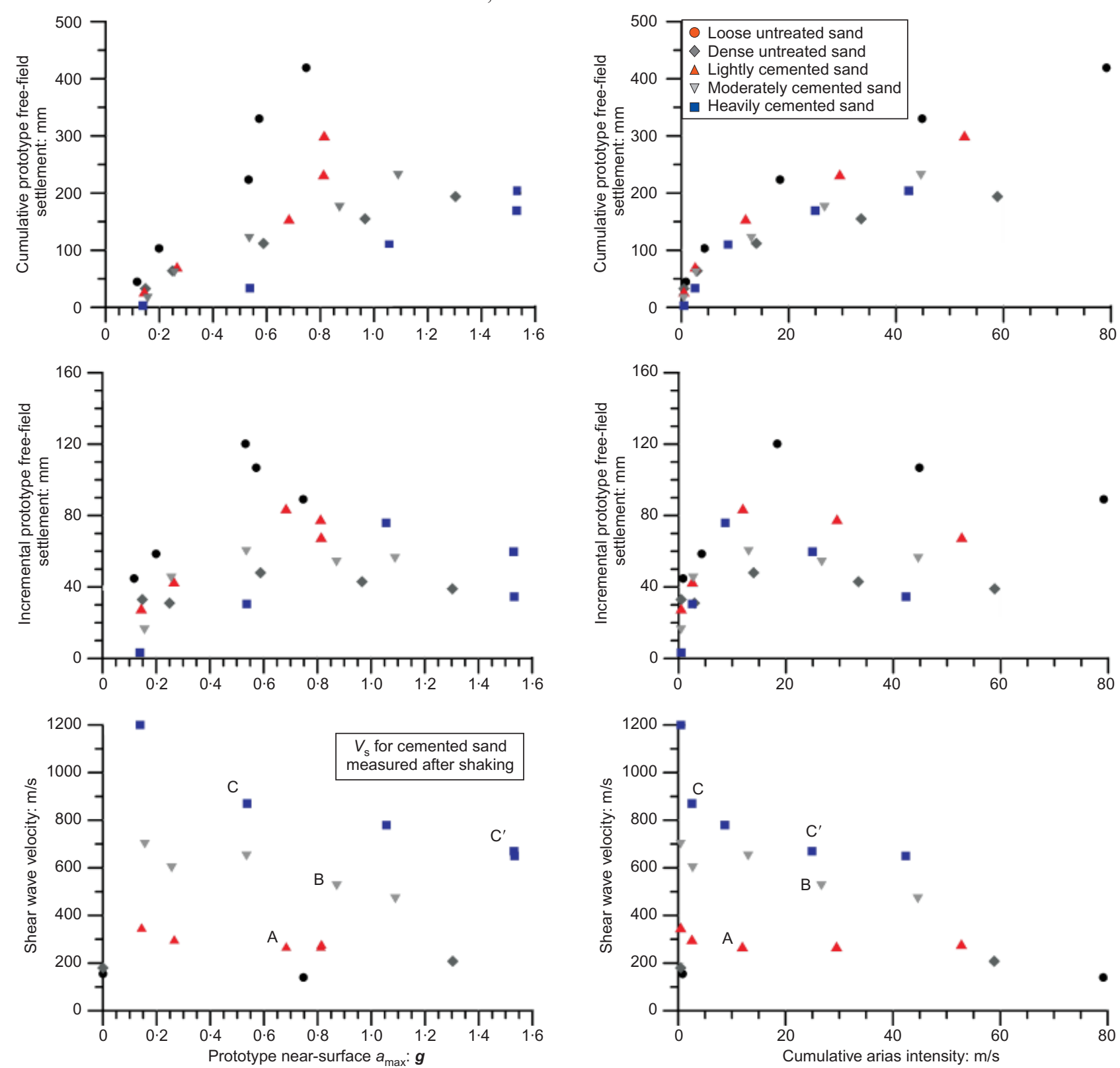

Fig. 9. Summary of free-field settlement and shear wave velocity related to the increasing prototype near-surface $a_{\max }$ and the cumulative arias intensity. The $V_{\mathrm{s}}$ measurements for the cemented sands are taken after the shaking events; the $V_{\mathrm{s}}$ measurements for the untreated sands are taken before the first shake and after the last shaking event. The shaking sequence used is outlined in Table 2

cemented sand does not show a peak value). The behaviour of both the cumulative and incremental settlement compared to $a_{\max }$ is highly dependent on the sequence of the shaking events. The data presented in Fig. 9 are applicable to the specific shaking sequence imposed, with increasing intensity packets of sine wave motions for each successive event. If a different order of shaking events was used (e.g. from high magnitude to low, or several events at the same magnitude) a different pattern of settlement would be expected.

The shaking-induced settlement data were also compared to the cumulative arias intensity of the surface motions during the shaking sequence (Fig. 9). The cumulative arias intensity represents the cumulative shaking sequence, and therefore the settlement trends are more independent from the specific shaking sequence used for the tests. The overall trends of the arias intensity plots agree with the settlement against near-surface $a_{\max }$ trends previously discussed: the MICP-treated sands have similar cumulative settlement values as the dense sand until significant cementation degrades (letters A, B and $\mathrm{C}^{\prime}$ in Fig. 9), at which point settlements begin to increase. The incremental settlement-arias intensity trends show a peak incremental settlement was reached for each soil (at an arias intensity of $20 \mathrm{~m} / \mathrm{s}$ or lower), which is similar to the near-surface $a_{\max }$ trends.

\section{Cyclic soil behaviour}

Cyclic direct simple shear (DSSc) tests were performed on MICP-treated soil to complement the centrifuge testing; the results of the MICP-treated soil were compared to that of the loose untreated sand. The loose sand specimen was cemented to a moderate level $\left(V_{\mathrm{s}}=650 \mathrm{~m} / \mathrm{s}\right.$; equivalent to the moderate level attained in the centrifuge test) and then subjected to cyclic loading. A detailed presentation of all of the DSSc data is provided in the Pacific Earthquake Engineering Research Center report (Faison \& Mahin, 2012).

A summary of the cyclic data is presented as the cyclic 
stress ratio (CSR) plotted against number of cycles to cause liquefaction $(N)$ curve (Fig. 10) (e.g. liquefaction is defined as $3 \%$ strain, which is comparable to the dynamic strains experienced during centrifuge testing). The MICP treatment provides a substantial increase in liquefaction resistance, with the CSR increasing by about $0 \cdot 3$ across the cycle number range examined. This increase in liquefaction resistance is consistent with the behaviour observed in the centrifuge test performed at the same moderate level of cementation. The CSR against $N$ relationship for the MICPtreated soils was developed based on a series of monotonic and multi-stage cyclic tests. The data point labelled A in Fig. 10 is an estimate made from the stress at which the treated specimen tested in monotonic direct simple shear had strained approximately 3\%. The test represented by data point $\mathrm{B}$ experienced unmeasured disturbance during the previous 2114 cycles of loading at a smaller stress level; therefore, the test would likely have required a larger number of cycles to fail without the prior disturbance. Points $\mathrm{C}$ and D on Fig. 10 are lower bound estimates, as additional cycles are needed to achieve $3 \%$ strain.

\section{CONCLUSIONS}

MICP treatment increased the cyclic strength and stiffness of the sand and provided sufficient improvement to resist liquefaction. Under dynamic loading, the MICP-treated soils showed reduced excess pore pressure generation at all levels of shaking, reduced settlements and generally greater peak surface accelerations compared to the untreated, loose saturated sand. Shaking-induced settlements were also lower than those observed in the untreated, loose sand model; the settlements of the MICP-treated soils were similar to or smaller than those of the dense, untreated sand until the cementation began to degrade, at which point the settlements were larger than the dense sand but still lower than the loose sand. The results of the centrifuge testing illustrate that the MICP treatment improves the soil behaviour under dynamic loading by reducing the generated pore pressures and shaking-induced settlements, but also increases the maximum accelerations at the ground surface. These results indicate the importance of evaluating the site response when considering MICP treatment. The changes to the soil behaviour

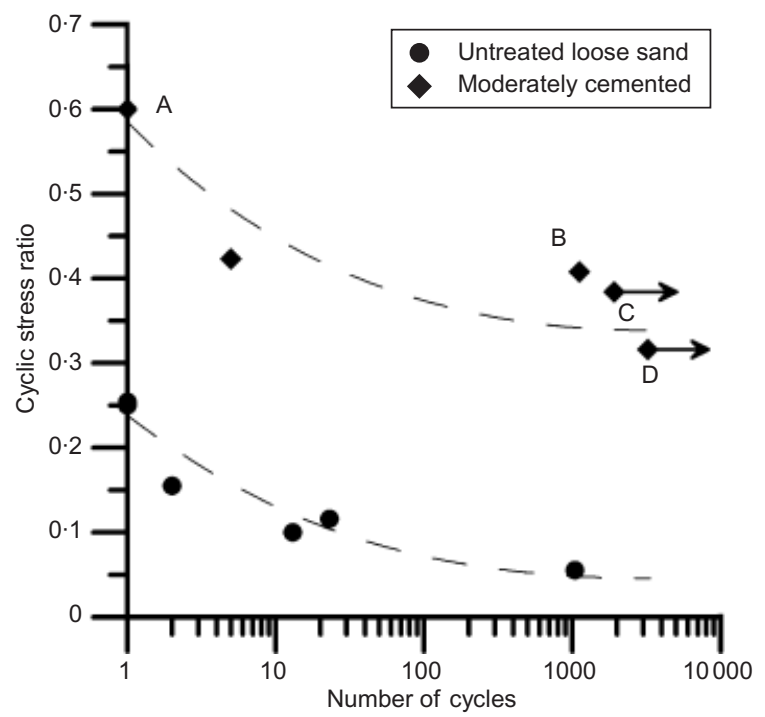

Fig. 10. Cyclic stress ratio plotted against number of cycles to reach liquefaction (defined as $3 \%$ strain for the cyclic direct simple shear (DSSc) tests (Idriss \& Boulanger (2008)). These results are from DSSc tests performed on untreated loose and moderately cemented sand and shear stiffness will affect the site response, as shown in the centrifuge tests; therefore, a tradeoff between improved liquefaction resistance and minimising undesirable amplified ground surface motions needs to be considered when designing the treatment level.

The centrifuge testing of the MICP-treated soils revealed a transition in soil behaviour from 'soil-like' to 'rock-like' behaviour. The cementation integrity testing indicated that as the cementation increased from an untreated soil $\left(V_{\mathrm{s}}=\right.$ $120 \mathrm{~m} / \mathrm{s})$ to a heavily cemented soil $\left(V_{\mathrm{s}}=800 \mathrm{~m} / \mathrm{s}\right)$, the shear stiffness dependency on confinement stress decreased until the stiffness was no longer dependent on confinement (e.g. 'rock like').

The MICP treatment process offers an alternative novel ground improvement method to reduce the liquefaction susceptibility and the damage associated with dynamic loading. This treatment process provides a way to target a cementation level (or stiffness level) that will provide the desired level of performance under dynamic loading, provided that the effects on dynamic site response are accounted for.

\section{ACKNOWLEDGEMENTS}

Funding from the National Science Foundation (CMMI0727463 and -0830182) is appreciated. The use of the Center for Geotechnical Modeling Facilities was made possible by support through NEEScomm at Purdue University through NSF award CMMI-0927178. Any opinions, findings and conclusions or recommendations expressed in this material are those of the authors and do not necessarily reflect the views of the National Science Foundation. The DSSc testing was performed as part of the PEER REU programme. The authors would also like to thank Doug Spitzer, Gail da Silva, Dr Daniel Wilson and the UC Davis NEES ES staff for their assistance.

\section{REFERENCES}

Brandenberg, S. J., Kutter, B. L. \& Wilson, D. W. (2008). Fast stacking and phase corrections of shear wave signals in a noisy environment. J. Geotech. Geoenviron. Engng 134, No. 8, 11541165.

Chou, J. C. \& Kutter, B. (2008). Nonlinear shear wave propagation in strain stiffening and strain softening soil. Proc. Geotech. Earthquake Engng and Soil Dynamics IV, Sacramento, CA, ASCE Geotechnical Special Publication 181 (CD-ROM).

DeJong, J. T., Fritzges, M. B. \& Nüsslein, K. (2006). Microbial induced cementation to control sand response to undrained shear. J. Geotech. Geoenviron. Engng 132, No. 11, 13811392.

DeJong, J. T., Mortensen, B. M., Martinez, B. C. \& Nelson, D. C. (2010). Bio-mediated soil improvement. Ecol. Engng 36, No. 2, $197-210$.

DeJong, J. T., Soga, K., Banwart, S. A., Whalley, W. R., Ginn, T., Nelson, D. C., Mortensen, B. M., Martinez, B. C. \& Barkouki, T. (2011). Soil engineering in vivo: harnessing natural biogeochemical systems for sustainable, multi-functional engineering solutions. J. R. Soc. Interface 8, No. 54, 1-15.

Faison, H. \& Mahin, S. A. (2012). The effect of microbially induced calcite precipitation on the liquefaction resistance of sand. In PEER 2011/10 - Earthquake engineering for resilient communities: 2011 PEER internship program research report collection. Berkeley, CA, USA: Pacific Earthquake Engineering Research Center.

Fujita, Y., Taylor, J. L., Gresham, T. T., Delwiche, M., Colwell, F., McLing, T. L., Petzke, L. M. \& Smith, R. W. (2008). Stimulation of microbial urea hydrolysis in groundwater to enhance calcite precipitation. Environ. Sci. Technol. 42, No. 8, 30253032 .

Hardin, B. O. \& Black, W. L. (1968). Vibration modulus of 
normally consolidated clay. J. Soil Mech. Found. Div., ASCE 94 No. 2, 353-369.

Idriss, I. M. \& Boulanger, R. W. (2008). Soil liquefaction during earthquakes, MNO-12. Oakland, CA, USA: Earthquake Engineering Institute.

Ishihara, K. (1985). Stability of natural deposits during earthquakes. Proc. 11th Int. Conf. Soil Mech. Found. Engng, San Francisco 2, 321-376.

Karol, R. H. (2003). Chemical grouting and soil stabilization, p. 558. New York, NY, USA: Marcel Dekker.

Kutter, B. L. (1995). Recent advances in centrifuge modeling of seismic shaking. Proc. 3rd Int. Conf. Recent Adv. Geotech. Earthquake Engng Soil Dynamics, University of Missouri-Rolla, Rolla, MO 2, 927-942.

Montoya, B. M., Gerhard, R., DeJong, J. T., Wilson, D., Weil, M., Martinez, B. C. \& Pederson, L. (2012). Fabrication, operation, and health monitoring of bender elements for aggressive environments. Geotech. Testing J. ASTM 35, No. 5, GTJ103300.

Mortensen, B. M., Haber, M. J., DeJong, J. T., Caslake, L. F. \&
Nelson, D. C. (2011). Effects of environmental factors on microbial induced calcium carbonate precipitation. J. Appl. Microbiol. 111, No. 2, 338-349.

Narayanan, K. R. (1999). Modeling the seismic response of stratified soil. MSc thesis, University of California, Davis, CA, USA.

Stokoe, K. H., Lee, S. H. H. \& Knox, D. P. (1985). Shear moduli measurements under true triaxial stresses. In Advances in the art of testing soils under cyclic conditions (ed. V. Khosla), pp. 166185. New York, NY, USA: ASCE.

Weil, M. H., DeJong, J. T., Martinez, B. C. \& Mortensen, B. M. (2011). Seismic and resistivity measurements for real-time monitoring of microbially induced calcite precipitation in sand. Geotech. Testing J., ASTM 35, No. 2, GTJ103365.

Whiffin, V. S., van Paassen, L. A. \& Harkes, M. P. (2007). Microbial carbonate precipitation as a soil improvement technique. Geomicrobiol. J. 25, No. 5, 417-423.

Youd, T. L. \& Holzer, T. L. (1994). Piezometer performance at the wildlife liquefaction site, California. J. Geotech. Engng 120, No. 6, 975-995. 